\title{
Spectroelectrochemical Characterization of Si-Bridged Diphenylamines: Influence of Si-Bridging upon Electronic Structures of Diphenylamines
}

\author{
Hidenobu NaKaO, Hideki HaYASHI, and Koichi OKITA \\ Advanced Materials Lab., Japan Chemical Innovation Institute, \\ 2-1-6 Sengen, Tsukuba, Ibaraki 305-0047, Japan
}

\begin{abstract}
Spectroelectrochemical properties of monosilane bridged diphenylamine (5,10-dihydro-2,8-diphenyl-5,10,10trimethylphenazasiline, Phenaz) and disilane bridged diphenylamine (2,8-diphenyl-10,11-dihydro-10,11-disila5,10,10,11,11-pentamethyldibenzo[ $b, f]$ azepine, DSiAzep) were investigated. The electrochemical oxidation of Phenaz was reversible and its cyclic voltammogram was almost the same shape as that of diphenylamine (DPA). The electrochemical oxidation of DSiAzep was followed by irreversible reactions leading to the cleavage of the Si-Si bond. On electrochemical oxidations of Phenaz and DPA, the formation of a stable radical cation was observed with UV-Vis spectroscopy. In comparison with the absorption characteristics of oxidized radical cations, it was seen that the oxidized radical cation of Phenaz was more delocalized than that of DPA. In the same way, absorption characteristics of oxidized DSiAzep were observed to be different from those observed in Phenaz and DPA.
\end{abstract}

(Received November 6, 2000; Accepted December 19, 2000)

Since many $\pi$-conjugated compounds have excellent characters, various applications have been proposed. ${ }^{1}$ More recently, organic devices have attracted much attention, and aromatic amines have been especially expected as the active layer of these devices to exhibit interesting optical and electrical properties. $^{2-4}$ While silicon-based materials and their polymers also have been a subject of recent interest in connection with their potential utility as organic devices because of singular opto-electronic properties which originate from the $\mathrm{Si}-\mathrm{Si} \sigma$ unit and $\pi$-electron system. ${ }^{5,6}$

Phenazasiline having silicon bridged diphenylamine structures has interesting properties. ${ }^{7-10}$ We have already reported that poly(phenazasiline) is effective as a hole transport layer of EL devices and electrochromic displays. ${ }^{11,12}$ In addition, comparing with that for poly(diphenylamine), we found that introduction of Si-bridging unit promoted the delocalization of oxidized radical cation in the polymer. ${ }^{12}$

To examine the effect of Si-bridging on the delocalization of radical cation, spectroelectrochemical properties of Si-bridged diphenylamines were studied in this work. A combination of cyclic voltammetry and in situ UV-Vis spectroscopy was used to measure simultaneous electric, optical and structural changes in the electrochemical reactions.

\section{Experimental}

\section{Reagents}

All the chemicals used were of reagent grade. Chemical structures of diphenylamine derivatives used in this study are shown in Fig. 1.

Bis(4-biphenylyl)methylamine DPA was prepared as follows. Under $\mathrm{N}_{2}$, a $6-\mathrm{mL}$ volume of THF solution of $1.0 \mathrm{M}$ phenylmagnesium bromide was added to a solution of $1.04 \mathrm{~g}$
(3.0 mmol) of bis(4-bromophenyl)methylamine, ${ }^{13}$ and $90 \mathrm{mg}$ of $\mathrm{NiCl}_{2}$ (dppp) in $20 \mathrm{~mL}$ of THF. After stirring under reflux for $24 \mathrm{~h}$, the reaction mixture was extracted with ether. The crude product was washed by methanol and the powder was collected and dried under vacuum. Yield was $0.61 \mathrm{~g}(60 \%)$. Data of DPA. ${ }^{1} \mathrm{H}-\mathrm{NMR}\left(\mathrm{CDCl}_{3}\right): \delta 7.0-7.8(\mathrm{~m}, 13 \mathrm{H}), 3.41(\mathrm{~s}, 3 \mathrm{H}) .{ }^{13} \mathrm{C}$ NMR $\left(\mathrm{CDCl}_{3}\right): \delta 148.10,140.82,134.14,128.75,127.87$, 126.68, 126.64, 120.68, 40.32. Anal. Found: C, 84.6; H, 6.1; N, 3.9\%. Calcd for $\mathrm{C}_{25} \mathrm{H}_{21} \mathrm{~N} \cdot \mathrm{H}_{2} \mathrm{O}: \mathrm{C}, 85.0 ; \mathrm{H}, 6.6 ; \mathrm{N}, 4.0 \%$. Compounds DSiAzep and Phenaz were also obtained; these were prepared by the Ni-catalyzed coupling of related dibromide with phenylmagnesium bromide. ${ }^{14}$ Yields were $52 \%$ and $19 \%$, respectively. Data of DSiAzep. ${ }^{1} \mathrm{H}-\mathrm{NMR}\left(\mathrm{CDCl}_{3}\right): \delta$ $7.0-7.8(\mathrm{~m}, 16 \mathrm{H}), 3.27(\mathrm{~s}, 3 \mathrm{H}), 0.38(\mathrm{~s}, 12 \mathrm{H}) .{ }^{13} \mathrm{C} \mathrm{NMR}$ $\left(\mathrm{CDCl}_{3}\right): \delta 157.70,141.24,139.55,138.62,133.20,129.24$, $128.72,127.19,127.05,123.01,43.40,-1.49,-4.25$. ${ }^{29} \mathrm{Si} \mathrm{NMR}$ $\left(\mathrm{CDCl}_{3}\right): \delta-21.86$. Anal. Found: $\mathrm{C}, 75.9 ; \mathrm{H}, 6.8 ; \mathrm{N}, 3.0 \%$. Calcd for $\mathrm{C}_{29} \mathrm{H}_{31} \mathrm{NSi}_{2} \cdot 0.5 \mathrm{H}_{2} \mathrm{O}: \mathrm{C}, 75.9 ; \mathrm{H}, 7.0 ; \mathrm{N}, 3.1 \%$. Data of
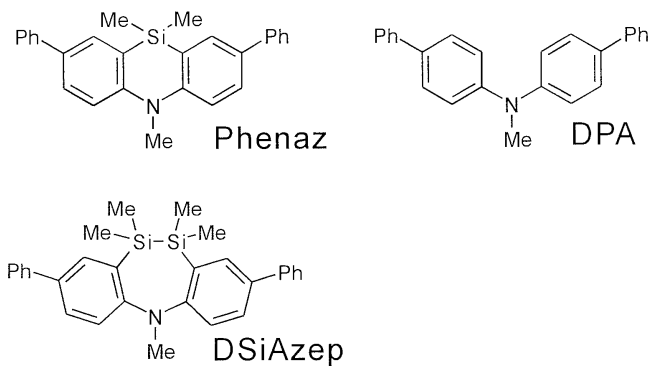

Fig. 1 Chemical structures of compounds. Phenaz, 5,10-dihydro2,8-diphenyl-5,10,10-trimethylphenazasiline; DPA, diphenylamine; DSiAzep, 2,8-diphenyl-10,11-dihydro-10,11-disila-5,10,10,11,11pentamethyldibenzo $[b, f]$ azepine. 


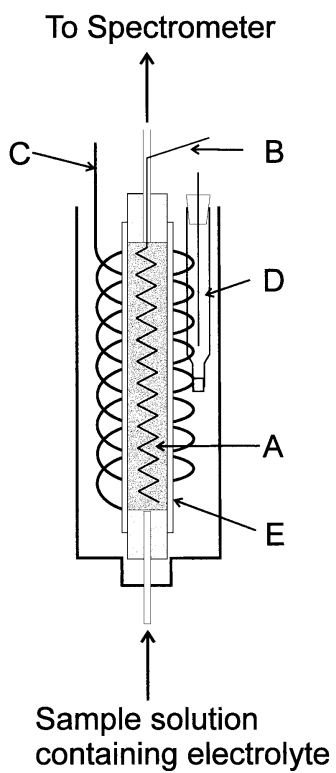

Fig. 2 Schematic diagram of the flow-through electrolysis cell: A, glassy carbon spheres; B, Pt-wire working electrode; C, stainlesssteel (SUS-304) wire counter electrode; $\mathrm{D}, \mathrm{Ag} / \mathrm{Ag}^{+}$reference electrode; E, Vycor glass tube.
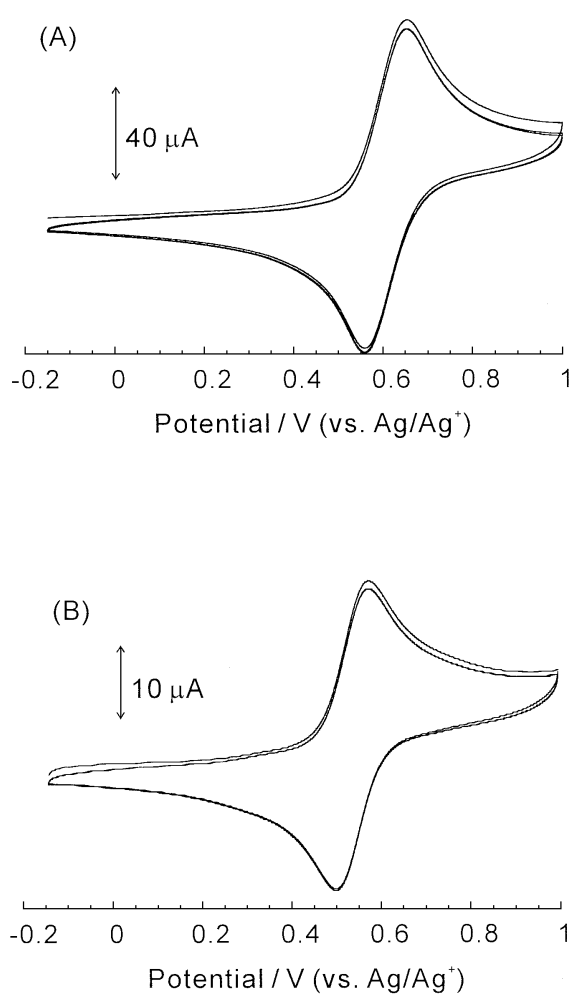

Fig. $3 \mathrm{CVs}$ of (A) $5 \mathrm{mM}$ Phenaz and (B) $1.2 \mathrm{mM}$ DPA in $0.1 \mathrm{M}$ TBAP in acetonitrile at $50 \mathrm{mV} / \mathrm{s}$.

Phenaz. ${ }^{1} \mathrm{H}-\mathrm{NMR}\left(\mathrm{CDCl}_{3}\right): \delta 6.9-8.0(\mathrm{~m}, 10 \mathrm{H}), 3.41(\mathrm{~s}, 3 \mathrm{H})$, $0.47(\mathrm{~s}, 6 \mathrm{H}) .{ }^{13} \mathrm{C} \mathrm{NMR}\left(\mathrm{CDCl}_{3}\right): \delta 150.15,141.03,133.18$, 131.90, 128.83, 128.79, 126.76, 126.65, 123.41, 115.46, 38.37, -1.91. ${ }^{29} \mathrm{Si} \mathrm{NMR}\left(\mathrm{CDCl}_{3}\right): \delta-21.46$. Anal. Found: $\mathrm{C}, 82.1 ; \mathrm{H}$, $6.5 ; \mathrm{N}, 3.3 \%$. Calcd for $\mathrm{C}_{27} \mathrm{H}_{25} \mathrm{NSi} \cdot 0.2 \mathrm{H}_{2} \mathrm{O}: \mathrm{C}, 82.1 ; \mathrm{H}, 6.5 ; \mathrm{N}$, $3.5 \%$.
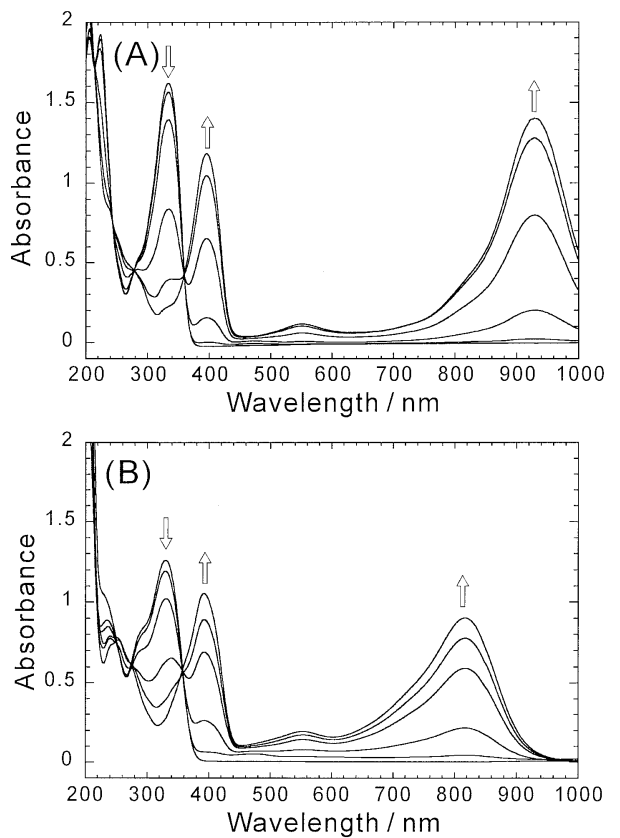

Fig. 4 Absorption spectral changes during oxidation at constant potentials. (A) $4.5 \times 10^{-5} \mathrm{M}$ Phenaz in acetonitrile containing $0.1 \mathrm{M}$ TBAP at $-0.15 \mathrm{~V},+0.5 \mathrm{~V},+0.55 \mathrm{~V}, 0.6 \mathrm{~V}, 0.65 \mathrm{~V}$ and $1 \mathrm{~V}$ in the arrow direction. (B) $4.0 \times 10^{-5} \mathrm{M}$ DPA in acetonitrile containing 0.1 M TBAP at $-0.15 \mathrm{~V},+0.45 \mathrm{~V},+0.5 \mathrm{~V},+0.55 \mathrm{~V},+0.6 \mathrm{~V}$ and $+0.8 \mathrm{~V}$ in the arrow direction.

\section{Cyclic voltammetry}

Elecrochemical control of the experiments was achieved using a BAS electrochemical analyzer Model 660. A three electrodes system was used, consisting of a glassy carbon (GC) electrode (BAS, $3 \mathrm{~mm}$ in diameter) as the working electrode, a platinum wire counter electrode, and an $\mathrm{Ag} / \mathrm{Ag}^{+}\left(10 \mathrm{mM} \quad \mathrm{AgNO}_{3}\right)$ reference electrode. The electrolyte solutions were $0.1 \mathrm{M}$ tetra$n$-buthylammonium perchlorate (TBAP) in dehydrated acetonitrile.

\section{Spectroelecrochemistry}

For in situ spectroelectrochemical measurements, a flowthrough electrolysis cell was used. ${ }^{15,16}$ Figure 2 shows a crosssectional diagram of a flow-through electrolysis cell. A Vycor glass tube (Giken Kagaku, $5 \mathrm{~cm}$ length $\times 7 \mathrm{~mm}$ o.d.) was used as a separator between the working and counter electrode compartments. The working electrode was a GC sphere (Tokai Carbon, $<100 \mu \mathrm{m}$ diameter) with a $0.2 \mathrm{~mm}$ Pt wire, a lead of the working electrode. The sample solution was carried into the cell by an IWAKI peristaltic pump PST- $100 \mathrm{~N}$ at $0.5 \mathrm{ml} / \mathrm{min}$, after that it was carried into the spectrometer. Each potential was maintained during spectrum measurements. By examining the oxidation of ferrocene, we found that the electrolysis using this flow cell was quantitative ( $>98 \%$ efficiency), and that the number of electrons transferred could be evaluated directly from the limiting current. Thus, each sample solution was electrolyzed completely before it reached the outlet of the cell.

\section{Results and Discussion}

Spectroelectrochemical properties of Phenaz

The cyclic voltammogram (CV) of Phenaz showed a reversible one-electron transfer process with $E^{\mathrm{o}^{\prime}}=0.605 \mathrm{~V}$ (Fig. 
(A) HOMO of Phenaz
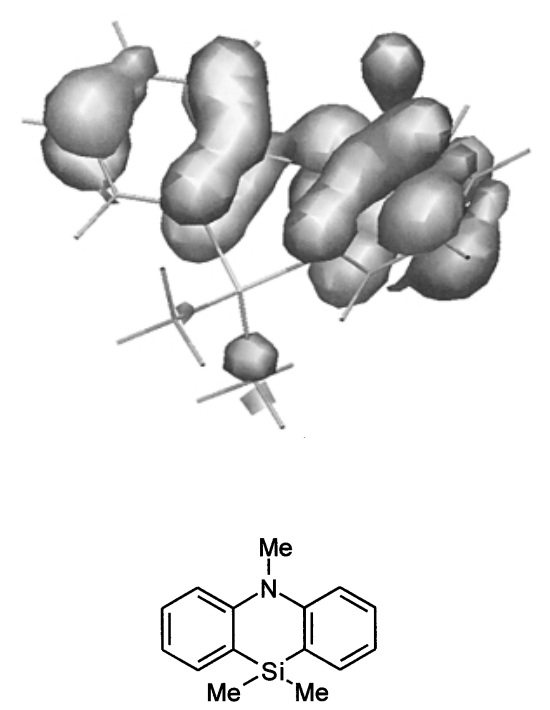

(B) HOMO of DSiAzep
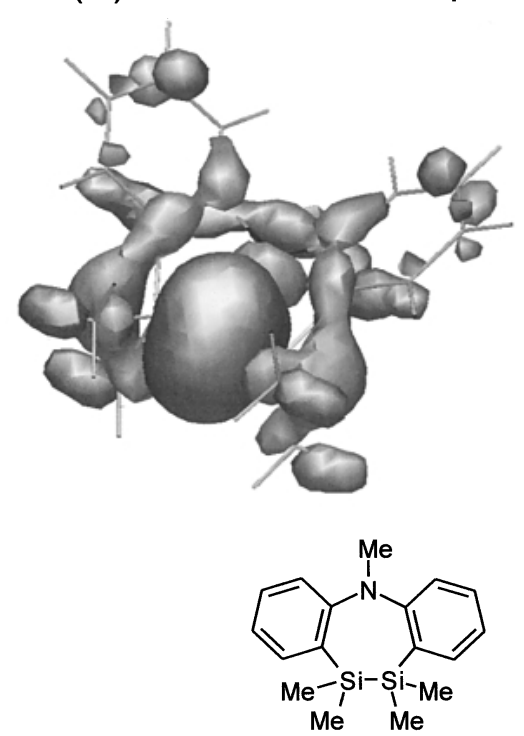

Fig. 5 Chemical structures of (A) Phenaz and (B) DSiAzep optimized by MOPAC/PM3 calculation. The end phenyl group of each compound was omitted in order to facilitate the calculation.

3(A)). On the oxidation of DPA, its voltammogram $\left(E^{0^{\prime}}=0.535\right.$ V) shown in Fig. 3(B) was almost the same as that of Phenaz. In addition, both $\mathrm{CV}$ s showed stable shapes during continuous potential scans. However, no clear response of $\mathrm{CV}$ of dimethyldiphenylsilane was observed in the measurement potential range. Consequently, the electron transfer reaction was achieved on the $\mathrm{N}$ atom, ${ }^{17-20}$ and the $\mathrm{Si}$ atom was irrelevant for the electrochemical oxidation of Phenaz.

UV-Vis spectroelectrochemistry was used to obtain further details regarding the oxidation processes. Figure 4(A) shows the absorption spectrum change of Phenaz in the potential change. The absorption maximum of neutral Phenaz around $334 \mathrm{~nm}$ decreased with an increase in potential, and then new absorption bands around $396 \mathrm{~nm}$ and $930 \mathrm{~nm}$ increased. These absorption bands achieved a maximum value at about $0.5 \mathrm{~V}$, which was near the anode peak potential as shown in Fig. 3(A). These bands are attributed to the absorption characteristics of oxidized radical cations of Phenaz $\left(\mathrm{Phenaz}^{+\cdot}\right)$, which are detected easily because of the stability of the delocalized radical cation as seen in its reversible voltammogram. ${ }^{17-20}$

The oxidation absorption change of DPA was also observed for comparison (Fig. 4(B)). The oxidation of DPA produces the radical cation ( $\mathrm{DPA}^{+\cdot}$ ), which has maxima at $392 \mathrm{~nm}$ and 817 $\mathrm{nm}$. From a comparison of the longer wavelength side $(>600$ $\mathrm{nm})$ of both radical cations, the absorption band of Phenaz ${ }^{+\cdot}(930$ $\mathrm{nm})$ is longer than that of $\mathrm{DPA}^{+\cdot}(817 \mathrm{~nm})$. This result indicates that delocalization in the molecular of Phenaz $^{+\cdot}$ occurs more easily than that of $\mathrm{DPA}^{+\cdot}$.

To understand the difference of delocalization of the two radical cations, we tried to examine from the molecular viewpoint. As described before, two benzene units of Phenaz through the $\mathrm{N}$ atom are fixed by the $\mathrm{Si}$ atom. According to the HOMO of Phenaz optimized by MOPAC/PM3 calculation (WinMOPAC Ver. 2.0, Fujitsu) as shown in Fig. 5(A), this compound has large orbitals on two benzene units through the $\mathrm{N}$ atom. On X-ray crystal analysis, however, since the sum of the bond angles around the $\mathrm{N}$ atom of Phenaz is $358.2^{\circ}$, it seems that the $\mathrm{N}$ atom has $\mathrm{sp}^{2}$-type properties. ${ }^{14}$ In other words, the bond angles around $\mathrm{N}$ atom of Phenaz are almost planar and this fact seems to be favorable to the delocalization of radical cations in the $\pi$-conjugation system. Results of spectroelectrochemical measurements and computer calculations for Phenaz showed that the Si-bridging enhances the delocalization of Phenaz ${ }^{+}$.

\section{Spectroelectrochemical properties of DSiAzep}

The CV of DSiAzep, disilane-bridged DPA, was shown in Fig. 6. Although CVs of Phenaz and DPA showed one reversible redox, that of DSiAzep was irreversible $\left(E_{\mathrm{pa}}=0.705\right.$ V). This irreversible behavior is widely observed for compounds having an $\mathrm{Si}-\mathrm{Si}$ bond, such as hexamethyldisilane $\left(\mathrm{Me}_{3} \mathrm{SiSiMe}_{3}\right)$, which involves $\mathrm{Si}-\mathrm{Si}$ bond cleavage. ${ }^{21-23}$ Furthermore, from the large difference in $\mathrm{CV}$ shapes between the first scan and the second scan, it seems that the oxidation reaction of DSiAzep is slower than those of Phenaz and DPA, as shown in Fig. 3. This phenomenon is attributed to the slow reaction with $\mathrm{Si}-\mathrm{Si}$ bond cleavage as inferred from the low value of transfer coefficient. ${ }^{21}$ On the other hand, since continuous $\mathrm{CV}$ curves at slower scan rates $(20 \mathrm{mV} / \mathrm{s})$ are very similar in shape (Fig. 6(B)), it seems that the electrochemical equilibrium is achieved completely within this potential scan time. Though it seems that $\mathrm{Si}-\mathrm{Si}$ bond cleavage occurs in electrochemical oxidation for DSiAzep, the reversible response of $\mathrm{N}$ atom observed in Fig. 3 is not shown clearly.

It is known that the electrochemical oxidation of $\mathrm{Me}_{3} \mathrm{SiSiMe}_{3}$ is a two-electron process. ${ }^{21}$ By using a flow-through electrolysis cell, the overall reaction for DSiAzep resulted in approximately 3.0 electrons per molecule. This result suggests that $\mathrm{Si}-\mathrm{Si}$ bond cleavage (a two-electron process) and $\mathrm{N}$ atom oxidation (an one-electron process) are occurring simultaneously on DSiAzep oxidation.

To understand the detailed oxidation mechanism of DSiAzep, spectrochemical properties were studied. On initial oxidation (from $-0.15 \mathrm{~V}$ to $0.55 \mathrm{~V}$ ), the absorption maximum of neutral DSiAzep at $263 \mathrm{~nm}$ decreased with an increase in potential, and then new absorption bands at $329 \mathrm{~nm}$ and $400 \mathrm{~nm}$ increased 

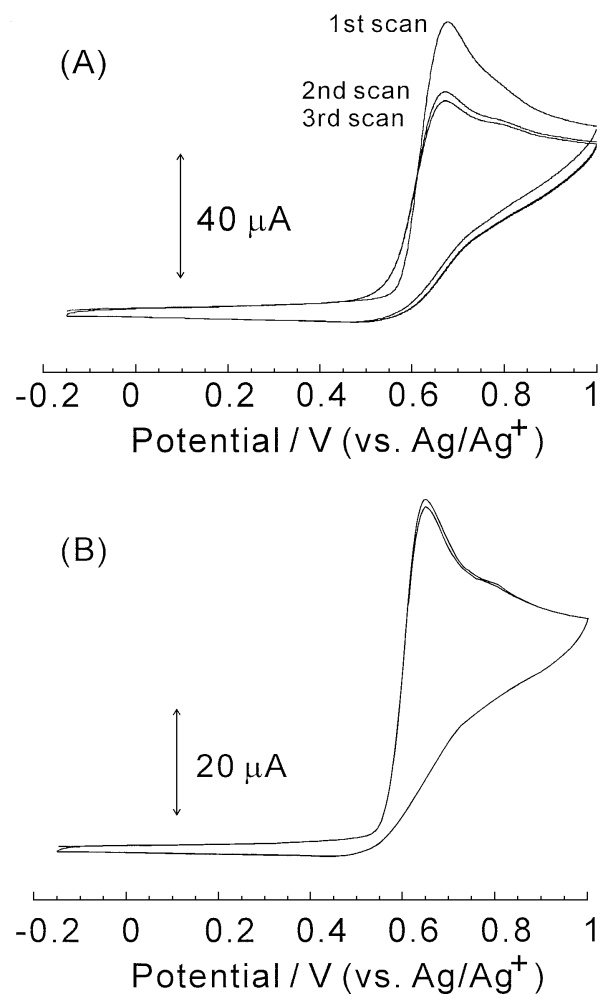

Fig. $6 \mathrm{CV}$ of $5 \mathrm{mM}$ DSiAzep in $0.1 \mathrm{M}$ TBAP in acetonitrile at 50 $\mathrm{mV} / \mathrm{s}(\mathrm{A})$ and $20 \mathrm{mV} / \mathrm{s}(\mathrm{B})$.
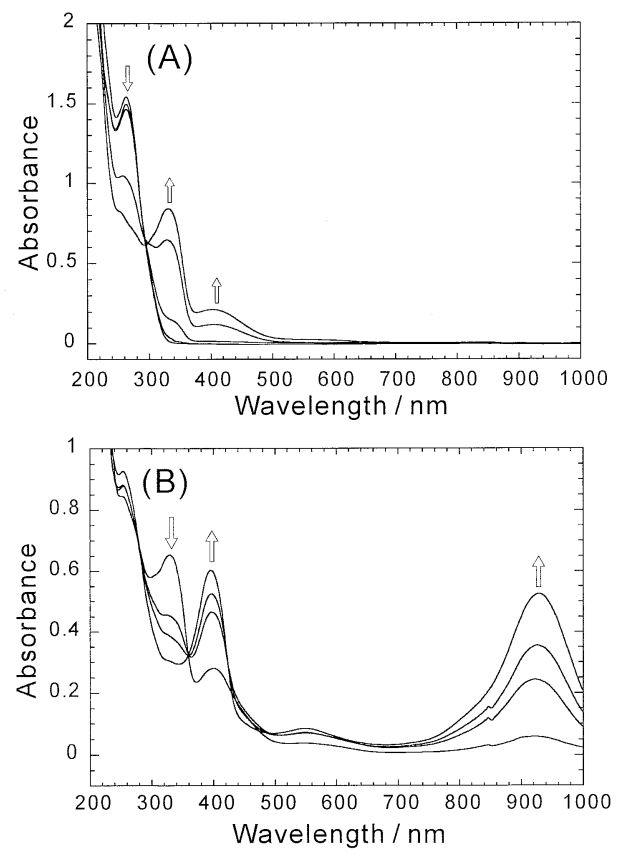

Fig. 7 Absorption spectral changes of $4.0 \times 10^{-5}$ M DSiAzep in acetonitrile containing $0.1 \mathrm{M}$ TBAP during oxidation at constant potentials. (A) $-0.15 \mathrm{~V},+0.4 \mathrm{~V},+0.45 \mathrm{~V},+0.5 \mathrm{~V}$ and $+0.55 \mathrm{~V} v s$. $\mathrm{Ag} / \mathrm{Ag}^{+}$in the arrow direction. (B) $+0.6 \mathrm{~V},+0.65 \mathrm{~V},+0.7 \mathrm{~V}$ and +0.9 $\mathrm{V}$ vs. $\mathrm{Ag} / \mathrm{Ag}^{+}$in the arrow direction.

(Fig. 7(A)). On the other hand, the cleavage for compounds having $\mathrm{Si}-\mathrm{Si}$ bonds is well known for photochemical processes involving UV irradiation. ${ }^{24,25}$ Since UV irradiation of DSiAzep in acetonitrile showed a decrease in absorption band at $263 \mathrm{~nm}$,
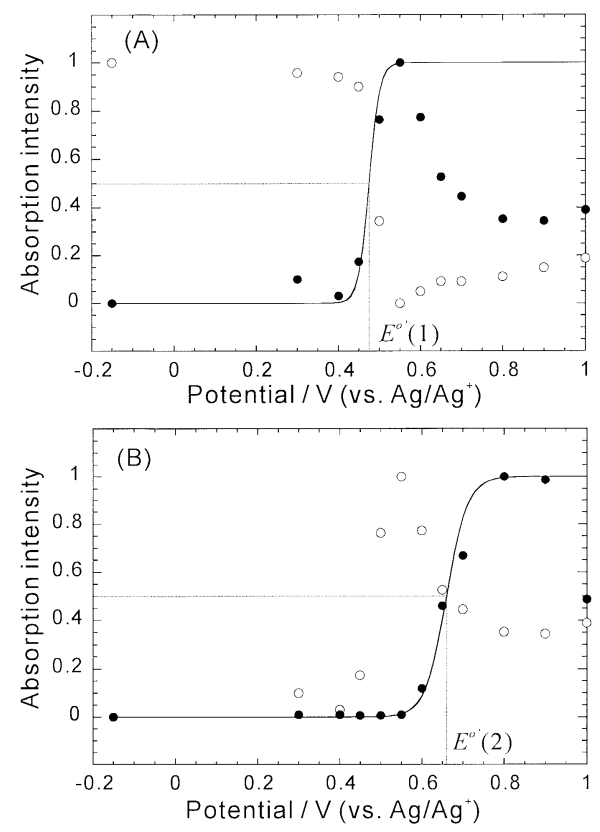

Fig. 8 Relative intensity changes of absorption spectra of DSiAzep induced by oxidation potentials. (A) Relative intensity changes: (O) at $263 \mathrm{~nm}$ and (•) at $329 \mathrm{~nm}$. (B) Relative intensity changes: (o) at $329 \mathrm{~nm}$ and (•) at $929 \mathrm{~nm}$

this absorption band was attributed to $\sigma-\sigma^{*}$ transition of $\mathrm{Si}-\mathrm{Si}$ bond. The absorption band at $329 \mathrm{~nm}$ is almost equal to the absorption band observed in the neutral state of Phenaz and DPA attributed to $\pi-\pi^{*}$ transition. Though the absorption band at $400 \mathrm{~nm}$ is not yet identified, it might be an intermediate produced on $\mathrm{Si}-\mathrm{Si}$ bond cleavage. ${ }^{21,24}$ Thus, it may be concluded that the initial oxidation for DSiAzep do not lead to the oxidation of $\mathrm{N}$ atom but to $\mathrm{Si}-\mathrm{Si}$ bond cleavage because of the absence of any absorption band attributed to radical cation on $\mathrm{N}$ atom.

Figure 8(A) shows a plot of relative changes in absorbance for DSiAzep at $263 \mathrm{~nm}$ and $329 \mathrm{~nm}$ against applied potential, $E_{\text {app }}$ and then the number of electrons involved in oxidation, $n$ and formal potential, $E^{o^{\prime}}$ are estimated by the Nernst equation (Eq. (1)):26-28

$$
E_{\text {app }}=E^{\mathrm{o}^{\prime}}+\frac{R T}{n F} \ln \left(\frac{[\mathrm{Ox}]}{[\mathrm{Red}]}\right)=E^{\mathrm{o}^{\prime}}+\frac{R T}{n F} \ln \left(\frac{[\mathrm{Ox}]}{1-[\mathrm{Ox}]}\right)
$$

where the concentration ratio for oxidized DSiAzep, [Ox] may be obtained as relative absorption changes at $329 \mathrm{~nm}$. As shown in Fig. 8(A), the experimental results agree well with $n=$ 2.0 and $E^{o^{\prime}}(1)=0.475 \mathrm{~V}$ by Eq. (1), and consequently, support the existence of an $\mathrm{Si}-\mathrm{Si}$ bond cleavage reaction.

On further oxidation $(>0.6 \mathrm{~V})$, the absorption band at $329 \mathrm{~nm}$ decreased and then new absorption band at $396 \mathrm{~nm}$ and $929 \mathrm{~nm}$ increased (Fig. 7(B)). Since this observation is similar to the behavior of Phenaz and DPA shown in Fig. 4, it seems that the delocalized radical cation involving $\mathrm{N}$ atom oxidation is generated. The relative changes in absobance at $329 \mathrm{~nm}$ and $929 \mathrm{~nm}$ were plotted against potential in Fig. 8(B). Furthermore, $n$ and $E^{o^{\prime}}(2)$ for $\mathrm{N}$ atom oxidation of DSiAzep were estimated to be 1.0 and $0.660 \mathrm{~V}$, respectively by Eq. (1). Consequently, the overall reaction mechanism for DSiAzep can be exemplified as Scheme 1.

From the above results, one can state that DSiAzep do not have aromatic amine properties because $\mathrm{N}$ atom oxidation 

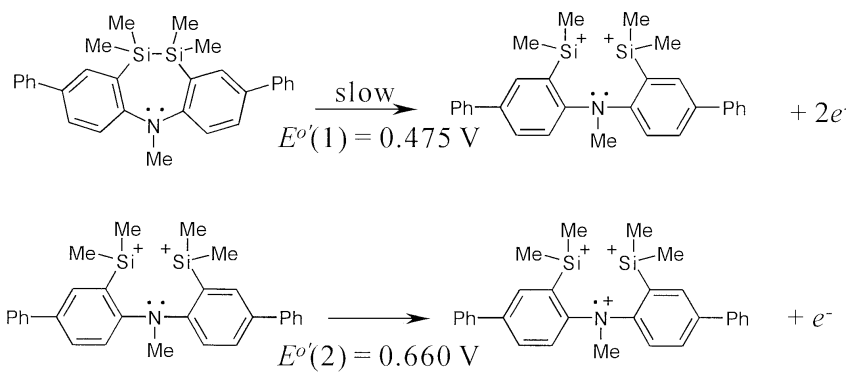

Scheme 1 Electrochemical oxidation process of DSiAzep.

occurs after Si-Si bond cleavage. Figure 5(B) shows HOMO of DSiAzep optimized by MOPAC/PM3 calculation, which has larger orbitals on $\mathrm{Si}-\mathrm{Si}$ bond than on two benzene units through $\mathrm{N}$ atom. Furthermore, X-ray analysis revealed that the sum of the angles around $\mathrm{N}$ atom is $337.8^{\circ} .{ }^{14}$ These results indicate that the $\mathrm{N}$ atom of DSiAzep has $\mathrm{sp}^{3}$-type properties, so the $\pi$ conjugation system seems not to be expanded through $\mathrm{N}$ atom.

We conclude that the Si-bridging exerts influence on the electronic structure of diphenylamine.

\section{Acknowledgements}

This work was supported by the New Energy and Industrial Technology Development Organization.

\section{References}

1. S. Saito, H. Sasabe, and T. Tsutsui, "Yuuki Denshi Zairyou (Organic Electronic Material, in Japanese)", 1990, Ohmsya, Tokyo, 83.

2. Y. Shirota, K. Okamoto, and H. Inada, Synth. Met., 2000, $111,387$.

3. M. Kimura, S. Inoue, K. Shimada, S. Tokito, K. Noda, and Y. Sawaki, Chem. Lett., 2000, 192.

4. Y. Sakamoto, T. Suzuki, A. Miura, H. Fujikawa, S. Tokito, and Y. Taga, J. Am. Chem. Soc., 2000, 122, 1832.

5. M. Fang, A. Watanabe, and M. Matsuda, J. Organomet. Chem., 1995, 489, 15.

6. M. Fang, A. Watanabe, and M. Matsuda, Chem. Lett.,
1994, 13.

7. Y. Ito, Jpn. Kokai, JP 08,302,339 (1996). [Chem. Abstr., 1997, 126, 97071e].

8. C. Tamborski, Ann. N. Y. Acad. Sci., 1965, 125, 242.

9. H. Kondo, M. Sato, and M. Yokoyama, J. Polym. Sci., Polym. Chem. Ed., 1983, 21, 165.

10. M. Mastragostino, A. Zanelli, G. Casalbore-Miceli, and A. Geri, Synth. Met., 1995, 68, 257.

11. H. Hayashi, H. Nakao, A. Adachi, H. Kimura, K. Okita, T. Hayashi, and M. Tanaka, Chem. Lett., 2000, 688.

12. H. Nakao, H. Hayashi, and K. Okita, Bunseki Kagaku, 2000, 49, 169.

13. E. D. Bergmann, Z. Aizenshtat, and I. Shahak, Tetrahedron, 1968, 24, 6449.

14. H. Hayashi, H. Nakao, S.-y. Onozawa, T. Hayashi, and K. Okita, submitted.

15. A. G. M. M. Hossain, T. Nagaoka, and K. Ogura, Electrochim. Acta, 1997, 42, 2577.

16. T. Nagaoka, T. Sasaki, K. Ogura, and T. Yoshino, J. Chem. Soc., Faraday Trans. 1, 1987, 83, 1823.

17. J. Niu, J. Y. Lee, A. Neudeck, and L. Dunsch, Synth. Met., 1999, 99, 133.

18. H. Yang and A. J. Bard, J. Electroanal. Chem., 1991, 306, 87.

19. E. T. Seo, R. F. Nelson, J. M. Fritsh, L. S. Marcoux, D. W. Leddy, and R. N. Adams, J. Am. Chem. Soc., 1966, 88, 3498.

20. C. P. Andrieux, I. Gallardo, and M. Junca, J. Electroanal. Chem., 1993, 354, 231.

21. A. Alberti, S. Dellonte, C. Paradisi, S. Roffia, and G. F. Peulli, J. Am. Chem. Soc., 1990, 112, 1123.

22. W. G. Boberski and A. L. Allred, J. Organometal. Chem. 1975, 88, 65 .

23. K. Mochida, A. Itani, M. Yokoyama, T. Tsuchiya, S. D. Worley, and J. K. Kochi, Bull. Chem. Soc., Jpn., 1985, 58 , 2149.

24. H. Sakurai, K. Sakamoto, and M. Kira, Chem. Lett., 1984, 1213.

25. M. Kira, K. Sakamoto, and H. Sakurai, J. Am. Chem. Soc., 1983, 105, 7469 .

26. W. R. Heineman, J. Chem. Edu., 1983, 60, 305.

27. M. Oyama, K. Nozaki, T. Nagaoka, and S. Okazaki, Bull. Chem. Soc. Jpn., 1990, 63, 33.

28. K. Kano and T. Ikeda, Anal. Sci., 2000, 16, 1013. 